\title{
Diagnosing vestibular hypofunction: an update
}

\author{
Dmitrii Starkov ${ }^{1,2,5} \cdot$ Michael Strupp ${ }^{3,4} \cdot$ Maksim Pleshkov ${ }^{1,2} \cdot$ Herman Kingma $^{1,2} \cdot$ Raymond van de Berg ${ }^{1,2}$
}

Received: 1 July 2020 / Revised: 31 July 2020 / Accepted: 1 August 2020 / Published online: 7 August 2020

(c) The Author(s) 2020

\begin{abstract}
Unilateral or bilateral vestibular hypofunction presents most commonly with symptoms of dizziness or postural imbalance and affects a large population. However, it is often missed because no quantitative testing of vestibular function is performed, or misdiagnosed due to a lack of standardization of vestibular testing. Therefore, this article reviews the current status of the most frequently used vestibular tests for canal and otolith function. This information can also be used to reach a consensus about the systematic diagnosis of vestibular hypofunction.
\end{abstract}

Keywords Bilateral vestibulopathy $\cdot$ Unilateral vestibulopathy $\cdot$ Video-oculography $\cdot$ Video-head impulse test $\cdot$ Caloric testing $\cdot$ Vestibular evoked myogenic potentials $\cdot$ Dynamic visual acuity $\cdot$ Perceptual threshold

\section{Introduction}

Vestibular hypofunction (also vestibulopathy, vestibular dysfunction, -hyporeflexia, -loss, -failure, -deficiency), i.e. a unilateral or a bilateral vestibulopathy, is a heterogeneous disorder of the peripheral and/or rarely central vestibular system leading typically to disabling symptoms such as dizziness, imbalance, and/or oscillopsia [1-3]. It affects up to 95 million adults in Europe and the USA [4]. Unfortunately, vestibular hypofunction is often missed or misdiagnosed. Fortunately, nowadays vestibular function of the semicircular canals and the otolith organs can be quantified, but there are still some diagnostic challenges [5-10]. For instance, no consensus has been reached regarding standardization of

Dmitrii Starkov

dmitrii.n.starkov@gmail.com

1 Division of Balance Disorders, Department of Otorhinolaryngology and Head and Neck Surgery, Maastricht University Medical Centre, Maastricht, The Netherlands

2 Faculty of Physics, Tomsk State Research University, Tomsk, Russia

3 German Center for Vertigo and Balance Disorders, Ludwig Maximilians University, Munich, Germany

4 Department of Neurology, Ludwig Maximilians University, Munich, Germany

5 Maastricht University ENT Department, P. Debyelaan 25, 6229 HX Maastricht, The Netherlands vestibular testing yet. This leads to a large variability in normative and pathologic cut-off values. Furthermore, not many vestibular laboratories have obtained their own normative values [11]. For the purpose of standardization, this article reviews the current status of the most clinically used vestibular tests. The topo-diagnostic value of posturography, despite its broad application, is already a long time under dispute, and for that reason not addressed in this review [12]. Finally, a new method for self-motion perception will be discussed.

\section{Video-oculography and electro-oculography}

Nowadays, video-oculography (VOG) is used as a routine method in clinical practice to quantitatively measure eye movements, whereas EOG has rarely applied anymore [13].

Using an infrared video camera, VOG detects eye movements by analyzing 2D images of the eye that is illuminated by infrared LEDs. The position of the pupil is calculated and used to track the horizontal and vertical eye movements, generally up to sample frequencies of $250 \mathrm{~Hz}$ or less [15]. Resolution and accuracy of VOG vary with image quality but are generally $<1^{\circ}$ in $2 \mathrm{D}$ over a gaze range of a minimum of $\pm 25^{\circ}$ horizontal and $\pm 20^{\circ}$ vertical, as long as the pupil is fully visible for the camera. Detection of torsional eye movements is based on the detection of rotation of the iris structure around the pupil center. This technique often fails as the image of the iris varies with gaze due to its 3D structure. Another possible alternative is to use a contact lens 
with markers [16]. However, this method is not common in practice and its clinical value is still to be determined.

Electro-oculography (EOG) is based on detecting the corneo-retinal potential [14-16] using electrodes placed around the eyes. An EOG resolution in 2D of typically $<1^{\circ}$ can be obtained over a gaze range of $\pm 30^{\circ}$ horizontal and $\pm 20^{\circ}$ vertical (although linearity only holds up to an eccentric gaze of $15-20^{\circ}$ ). The most frequently used sample frequency is 50-250 Hz. Accuracy (detection of absolute eye position) is limited due to substantial drift that often occurs. Frequent recalibrations are required as corneo-retinal potentials and EOG amplitudes vary by a factor of 4-5 with low versus bright ambient light intensity. Above $100 \mathrm{~Hz}$ the signal-tonoise-ratio often decreases by an increasing contribution of other electrophysiological signals such as EMG [17].

VOG and EOG systems both meet requirements for clinical use in terms of their accuracy and sensitivity of approximately $1^{\circ}$. There does not seem to be a "best method", but VOG can be easily applied in clinical practice and is, therefore, most often used. The preferred method of choice depends on how clinicians and/or technicians weigh the pros and cons of each technique with respect to their own requirements and patient population.

\section{The video-head impulse test (vHIT)}

The video-head impulse test (vHIT) is able to quantitatively assess the vestibulo-ocular reflex (VOR) of all six semicircular canals in the high-frequency domain and it can be used in acute, episodic and chronic vestibular syndromes [6, 18, 19]. However, it does not purely test one vestibular organ: some contribution from the other side remains [6]. vHIT is a much more sensitive and specific test than the clinical HIT [20]. The commercially available vHIT-devices differ regarding patient comfort, the accuracy of pupil detection, and methods for quantifying the VOR.

The accuracy of pupil detection can be affected by incorrect camera adjustment, poor calibration, blinking, eyelashes, narrow eyelids, poor illumination, mascara, spontaneous nystagmus, and goggle slippage. These factors can cause recording artifacts that might not be detected by the software and which could negatively influence the reliability of test outcomes [21-25]. Training of examiners is, therefore, imperative, since it significantly reduces artifacts [26]. The number of impulses required to achieve reliable results can be reduced to two in the case of artifact-free traces, which is especially important when testing very young children with relatively little attention [27]. The VOR is quantified by calculating gain. VOR gain is the measure that illustrates to which extent eye movements (produced by the VOR) compensate for head movements. However, all commercially available devices use different gain calculation methods, which can lead to significant discrepancies in results [28, 29]. Two methods have been proposed to standardize gain calculation and to lower variability in results [30], but they are not (yet) routinely implemented in the clinic. Gain is also influenced by head velocity (higher velocity, lower gain) [31], target distance (shorter distance, higher gain) [32]), and (in the case of goggles) a direction bias for the side on which the camera is placed (higher gains for the side with the camera [25]). It is, therefore, advised to standardize these variables as much as possible in the clinic. If no normative data is available, absolute gain values below 0.8 can be considered pathological [33].

The vHIT is able to detect corrective saccades appearing during and after head impulses (covert and overt saccades, respectively). An earlier timing $[34,35]$ and a higher level of grouping (clustering regarding timing, quantified using the PR-score) of saccades might be indicative of compensation and might be correlated with a lower handicap in patients with vestibular hypofunction [36-40]. However, corrective saccades do not only reflect clinically relevant vestibular hypofunction or compensatory mechanisms: small saccades also appear in healthy subjects, especially with increasing age [41].

The Suppression Head Impulse Paradigm (SHIMP) was proposed to overcome the problem of covert saccades regarding gain calculation [42, 43]. SHIMP differs from vHIT with respect to the target: it moves along with the head. In this case, the presence of corrective saccades indicates the presence of vestibular function [42], while the absence of corrective saccades indicates impaired vestibular function [44]. VOR gain with SHIMP is significantly lower than with vHIT, which might (partially) be explained by age and VOR inhibition strategies during SHIMP [45, 46]. SHIMPs significantly reduce covert saccades, but not all of them. Furthermore, vHIT alone seems to be sufficient for detecting bilateral vestibulopathy regardless of the presence of covert saccades (van Dooren et al., in preparation).

\section{Testing of Dynamic Visual Acuity}

The visual acuity during dynamic conditions (e.g. walking) is called "dynamic visual acuity" (DVA). An impaired VOR (especially bilaterally) causes blurred vision during head movements. This can result in loss of DVA.

The DVA loss is quantified by the difference in visual acuity in static and dynamic conditions, which is measured using optotype charts or computerized DVA systems [7, 47]. The dynamic conditions can involve walking or active/passive head movements while sitting or standing. In case of impaired VOR, DVA loss is generally higher for passive head movements than for active head movements $[48,49]$. Contradictory evidence exists regarding the influence of age 
on DVA: it is either weak or absent [50-53]. Nevertheless, age decreases the ability to accomplish DVA testing on a treadmill in bilateral vestibulopathy patients and healthy subjects [53].

Recently, a new test for high-frequency DVA was proposed: the functional head impulse test (fHIT) [54-56]. During fHIT, the test subject is placed in front of a computer screen and head impulses are applied in the tested plane. When head acceleration exceeds a predefined threshold, a Landolt ring optotype appears for a predefined short time on the screen. After the impulse, the subject is instructed to choose its orientation using a keyboard. The percentage of correct answers is used as the output of the test. The test has shown effectiveness when evaluating acute unilateral vestibulopathy [57] and the effect of a prototype vestibular implant [58]. Although fHIT moderately correlates with oscillopsia severity, no correlation was observed between fHIT and the DVA test on a treadmill [59]. These tests seem complementary and do not substitute for each other.

DVA is a functional outcome of all systems involved: VOR, the oculomotor system, and central processing of signals [59]. For instance, internal feed-forward commands can mediate gaze [60], gait stabilization strategies can help to reduce head oscillations [61], and covert saccades improve DVA in patients with unilateral vestibulopathy [34, 62]. Therefore, DVA testing is mainly suited for evaluating the functional state of the vestibular system and compensation strategies, not for diagnosing peripheral vestibular deficits.

\section{Caloric testing}

Caloric testing is a widely used method to selectively assess vestibular function on each side in the low-frequency domain $(\sim 0.003 \mathrm{~Hz})$, using bithermal $\left(30{ }^{\circ} \mathrm{C}\right.$ and $\left.44{ }^{\circ} \mathrm{C}\right)$ caloric irrigations with water (the preferred stimulus) or air $[5,8,63]$. To optimize stimulation, horizontal canals are aligned with the vertical plane by asking the test subject in a supine position to tilt the head $20^{\circ}-30^{\circ}$ [64]. Irrigations of sufficient volume $(>250 \mathrm{ml}$ ) should last at least $30 \mathrm{~s}$ and can be performed in any order [65-67]. For the sake of standardization, it is advised to use cold irrigation first on the right, followed by cold on the left, then warm on the right, and finally warm on the left. A 5 min interval between the four successive irrigations can be used to avoid residual effects of the previous irrigation [68]. The slow phase velocity (SPV) of the caloric nystagmus is measured for each irrigation. In symptomatic patients, the sum of the bithermal maximum peak SPV $<6 \%$ s can be considered a diagnostic criterion for bilateral vestibulopathy and the sum of bithermal maximum peak SPV on each side between 6 and $25^{\circ} / \mathrm{s}$ for presbyvestibulopathy (when also age $\geq 60$ years) [1]. The upper limits for both vestibular asymmetry and directional preponderance can be set at $20 \%$ when no normative data is available [65, 69]. Poor attention, poor alertness, visual suppression, and unreliable eye movement detection often lead to false-positive findings of vestibular hypofunction [5].

Complete vestibular areflexia cannot be identified using ice water calorics, since the test mostly only evaluates lowfrequency horizontal canal function [70-72]. Moreover, ice water calorics itself might induce an irrelevant latent spontaneous nystagmus in a non-specific way [5].

\section{Rotatory chair testing}

Rotatory chair tests are generally used to assess horizontal semicircular canal function in the low- and middle-frequency domains. Two types of tests are mainly performed: the Torsion Swing Test (TST) and the Velocity Step Test (VST).

The TST is divided into the Sinusoidal Harmonic Acceleration Test (SHAT), which involves a single frequency sinusoidal stimulus, and the Pseudo-Random Rotation Test (PRRT), which involves sinusoidal stimuli with different frequencies. VST uses a slow acceleration (e.g. $\leq 2 \% \mathrm{~s}^{2}$ ) to reach a constant velocity (often $100 \%$ s) followed by an abrupt deceleration (e.g. $200^{\circ} / \mathrm{s}^{2}$ ). The VST mainly tests the excited canal, though a contribution of the contralateral canal to the total response still remains [73]. The VST is believed to be closer to the frequency spectrum of most natural head movements than TST [5, 9, 74]. Eyes should be open during testing since eye closure reduces the VOR response [75].

The outputs for SHAT are gain (ratio of slow phase eye velocity to chair velocity), phase (time relation between eye and chair velocities), and directional preponderance (asymmetry in magnitude/gain for left and right rotations), whilst for VST the time constant (time for nystagmus to decay to $37 \%$ of its peak magnitude) and gain are most relevant [9]. Since the gain is frequency-dependent, each frequency tested by SHAT or PRRT has its own normative values [76-78]. Phase and time constant are very stable parameters: no large inter-laboratory differences are observed [79]. A reduced gain and/or time constant reflect a unilateral or bilateral vestibulopathy, attention deficit, or visual suppression. A high gain and/or long time constant indicate hypersensitivity (anxiety and or hyperventilation during the test, or central pathology leading to disinhibition) [80, 81]. In addition, the product of gain and time constant seems to better reflect the impairment of the vestibular system than gain and time constant alone [82]. Abnormalities of phase and time constant can point to peripheral (e.g. bilateral vestibulopathy) and/or central vestibular disorders. The presence of a directional preponderance indicates a dynamic VOR asymmetry. This is often seen in uncompensated peripheral vestibular disorders and central vestibular disorders and provides insights into 
the central processing of vestibular input from both labyrinths $[5,9,74,77,83-89]$.

\section{Vestibular evoked myogenic potentials}

Vestibular evoked myogenic potentials (VEMP) are believed to reflect the otolith function $[10,90]$.

Air-conducted sound or bone-conducted vibration of the skull induces otolith vestibular responses, resulting in VEMP, which can be recorded using electromyography. Two types of VEMP are currently measured: cervical VEMP (cVEMP) and ocular VEMP (oVEMP). cVEMP mainly evaluate saccular function by measuring the inhibitory response from the ipsilateral sternocleidomastoid muscle. Therefore, the muscle should be contracted during the test. However, differences in muscle contraction can lead to inter- and intrasubject variabilities in response, hindering thorough evaluation [91-94]. Multiple methods have been proposed that effectively reduce variability, although none of them are (yet) widely applied in clinical practice [93, 94]. oVEMP mainly evaluates utricular function by measuring the excitatory response from the contralateral inferior oblique extra-ocular muscle. Standardized upward gaze is necessary to bring the eye muscles in close contact with the electrodes placed below the eyes [10,90]. Regarding stimuli, air-conducted sound (cVEMP) and bone-conducted vibration (oVEMP) are the preferred stimuli to detect vestibular hypofunction, although air-conducted sound is preferred to detect vestibular hyperfunction (e.g., superior semicircular canal dehiscence syndrome). For air-conduction, obtained results should be corrected for the present air-bone gap in cases with ipsilateral conductive hearing loss [95]. The air-conducted and bone-conducted stimuli mostly involve $500 \mathrm{~Hz}$ stimuli presented at a rate of $5 \mathrm{~Hz}$ to obtain optimal responses, although VEMP can be tested at different frequencies to obtain more insights into specific disease patterns [96] (e.g., testing a range from 250 to $1000 \mathrm{~Hz}$ ). Furthermore, increasing the stimulation rate from 5 to $13 \mathrm{~Hz}$ has been shown to produce reliable cVEMP thresholds, while decreasing testing time and subject discomfort [94].

Electromyographic responses of VEMP include two peaks of vestibular origin, which appear at approximately 13 and $23 \mathrm{~ms}$ in cVEMP, and at approximately 10 and $15 \mathrm{~ms}$ in oVEMP. Peaks appearing later in time have mixed and/ or different origins including vestibular, stretch reflex and cochlear [97, 98]. Outcome parameters used for VEMP are the presence of the response, the threshold (in $\mathrm{dB}$ ), peakto-peak amplitude $(\mu \mathrm{V})$, peak latency $(\mathrm{ms})$, and interaural asymmetry ratio. The testing paradigm and interpretation of VEMP are not yet standardized [99-102]. For correct interpretation, it is strongly advised to obtain age-matched normative data [11], since with age the amplitudes and response rates decline [103]. This implies that absent responses also appear in non-symptomatic healthy individuals, especially above the age of 60 years old [104]. The role of VEMP in clinical practice has been investigated extensively regarding diagnostics, prognosis, and monitoring of vestibular disorders [105, 106].

The most important clinical application of the VEMP is the syndromes of the third mobile window, including superior canal dehiscence syndrome (SCDS, see below) [106-108]. The relevance of VEMP in Menière's disease, unilateral and bilateral vestibulopathy, vestibular migraine, BPPV, and auditory neuropathy is very limited or not relevant [104, 109-116]. In SCDS, VEMP amplitudes are increased and VEMP thresholds are lowered on the affected side(s), as a result of a third mobile window [117]. To diagnose SCDS, using oVEMP amplitudes higher than $16.7 \mu \mathrm{V}$ as cut-off point results in a sensitivity of $100 \%$ and a specificity of $89 \%$ [118]. Regarding cVEMP thresholds, $2000 \mathrm{~Hz}$ tone burst stimuli show the best diagnostic accuracy, with sensitivities equal to or higher than $92 \%$ and a specificity of $100 \%$ [119]. Taking into account all the existing evidence about the use of VEMP to diagnose SCDS, oVEMP seems to be more sensitive and specific than cVEMP [108].

\section{Perceptual threshold testing}

Self-motion perception was first measured by Mach in the 19 th century [120]. Currently used methods to measure self-motion perceptual thresholds involve devices such as hydraulic or electric moving platforms [121, 122] or sleds [123]. To test self-motion perceptual thresholds, the subject is seated on a chair mounted on the platform or sled. Visual, auditory and somatosensory input are decreased as much as possible by, e.g., testing in darkness, wearing headphones, and covering skin surfaces [124]. The platform or sled then accelerates into the tested plane of motion, with the desired stimulus parameters (magnitude, frequency, etc.). After each stimulus, the subject has to indicate whether the movement was perceived. The main outcome parameter is the self-motion perceptual threshold representing the minimal value of a physical stimulus that can still be perceived [125, 126]. There are two types of perceptual thresholds: detection thresholds (motion is perceived: yes/no), and recognition thresholds (type and direction of motion).

In healthy subjects, self-motion perceptual thresholds are higher than horizontal VOR-thresholds, indicating a higher sensitivity of the brainstem than vestibulothalamic pathways [127]. Furthermore, self-motion perceptual thresholds increase after the age of 40 [121, 122], are frequency-dependent (lower thresholds at higher frequencies) [124], decrease with visual input [128], depend on stimulus profile $[129,130]$ and some thresholds might be affected 
by vestibular disorders such as Menière's disease (higher thresholds) and vestibular migraine (lower thresholds) [131-133]. The peripheral vestibular system strongly contributes to self-motion perceptual thresholds (especially rotations), as shown by significantly higher thresholds in patients with bilateral vestibulopathy compared to a control group [133-135]. One of the disadvantages of testing self-motion perception is the substantial time needed to complete testing for one subject (several hours). Recently, a faster method to determine self-motion perceptual thresholds was proposed, which facilitates testing of 12 motion types within $1 \mathrm{~h}$. The clinical value of tests for vestibular perception is not yet fully determined. However, since they can be of direct functional relevance, they might develop in the future into the "speech audiogram" for vestibular disorders $[5,121]$.

\section{Detecting vestibular hypofunction: a proposal}

To reliably detect vestibular hypofunction, normative laboratory values should be obtained for each test (if possible) and technicians should be trained [11].

When vestibular hypofunction is suspected, it might be recommended to start with vHIT due to its low burden for the test subject. If vHIT results are abnormal, no other vestibular testing is necessary. However, in case of normal vHIT results, performing caloric testing might be advisable, since caloric testing seems to be more sensitive than vHIT in detecting vestibular hypofunction in some vestibular disorders, in particular Menière's disease [136-139]. Furthermore, a dissociation between caloric testing and vHIT might be present, especially in cases with endolymphatic hydrops due to altered mechanics of the inner ear [140-143]. In case of bilateral vestibulopathy, rotatory chair testing can be added to increase the specificity of testing (not sensitivity) $[80,144]$ and to help to determine residual vestibular function [82], since the responses to rotatory chair testing are often better preserved than the responses to vHIT or caloric stimulation [144]. Dynamic visual acuity testing is recommended for evaluation of the functional state of the vestibular system as well as compensatory processes occurring over time. VEMP is currently only advised for detecting superior canal dehiscence syndrome.

\section{Conclusion}

Most recently published literature involves refinement or development of vestibular laboratory tests. However, no worldwide consensus has been reached yet on standardized testing procedures and normative values for any of the tests discussed in this article. Standardization will most likely improve the reliability and reproducibility of vestibular laboratory test results.

Funding Not applicable

Availability of data and materials Not applicableCode availability Not applicable.

\section{Compliance with ethical standards}

Conflicts of interest/Competing interests The authors declare that they have no conflict of interest.

Ethics approval Not applicable.

Consent to participate Not applicable.

Consent for publication Not applicable.

Open Access This article is licensed under a Creative Commons Attribution 4.0 International License, which permits use, sharing, adaptation, distribution and reproduction in any medium or format, as long as you give appropriate credit to the original author(s) and the source, provide a link to the Creative Commons licence, and indicate if changes were made. The images or other third party material in this article are included in the article's Creative Commons licence, unless indicated otherwise in a credit line to the material. If material is not included in the article's Creative Commons licence and your intended use is not permitted by statutory regulation or exceeds the permitted use, you will need to obtain permission directly from the copyright holder. To view a copy of this licence, visit http://creativecommons.org/licenses/by/4.0/.

\section{References}

1. Strupp M, Kim J-S, Murofushi T et al (2017) Bilateral vestibulopathy: diagnostic criteria Consensus document of the Classification Committee of the Bárány Society. J Vestib Res 27:177189. https://doi.org/10.3233/VES-170619

2. Lucieer F, Duijn S, Van Rompaey V et al (2018) Full spectrum of reported symptoms of bilateral vestibulopathy needs further investigation-a systematic review. Front Neurol 9:352. https:// doi.org/10.3389/fneur.2018.00352

3. Zee DS, Yamazaki A, Butler PH, Gucer G (1981) Effects of ablation of flocculus and paraflocculus on eye movements in primate. J Neurophysiol 46:878-899. https://doi.org/10.1152/ jn.1981.46.4.878

4. Grill E, Heuberger M, Strobl R et al (2018) Prevalence, determinants, and consequences of vestibular hypofunction. Results from the KORA-FF4 survey. Front Neurol. https://doi.org/10.3389/ fneur.2018.01076

5. van de Berg R, van Tilburg M, Kingma H (2015) Bilateral vestibular hypofunction: challenges in establishing the diagnosis in adults. ORL J Otorhinolaryngol Relat Spec 77:197-218. https:// doi.org/10.1159/000433549 
6. Halmagyi GM, Chen L, MacDougall HG et al (2017) The Video Head Impulse Test. Front Neurol 8:258. https://doi.org/10.3389/ fneur.2017.00258

7. Herdman SJ, Tusa RJ, Blatt $P$ et al (1998) Computerized dynamic visual acuity test in the assessment of vestibular deficits. Am J Otol 19:790-796

8. Barany R (1906) Untersuchungen uber den vom Vestibularapparat des Ohres reflectorisch ausgelosten rhythmischen Nystagmus und seine Begleiterscheinungen, 40th edn. Oscar Coblentz, Berlin

9. Furman JM (2016) Rotational testing. In: Handbook of Clinical Neurology. Elsevier B.V., pp 177-186

10. Curthoys IS, Dlugaiczyk J (2020) Physiology, clinical evidence and diagnostic relevance of sound-induced and vibration-induced vestibular stimulation. Curr Opin Neurol 33:126-135

11. Strupp M, Grimberg J, Teufel J et al (2019) Worldwide survey on laboratory testing of vestibular function. Neurol Clin Pract. https://doi.org/10.1212/cpj.0000000000000744

12. Kingma H, Gauchard GC, De Waele C et al (2011) Stocktaking on the development of posturography for clinical use. J Vestib Res Equilib Orientat 21:117-125. https://doi.org/10.3233/ VES-2011-0397

13. Ganança MM, Caovilla HH, Ganança FF (2010) Electronystagmography versus videonystagmography. Braz J Otorhinolaryngol 76:399-403

14. Baloh RW, Honrubia V, Kerber A (2011) Clinical neurophysiology of the vestibular system, 4th edn. Oxford University Press, Oxford

15. Carpenter RHS (1988) Movements of the eyes, 2nd edn. Pion Limited, London

16. Feynman RP (Richard P, Leighton RB, Sands ML (Matthew L (1989) The Feynman lectures on physics. Addison-Wesley

17. van Schooten KS, Sloot LH, Bruijn SM et al (2011) Sensitivity of trunk variability and stability measures to balance impairments induced by galvanic vestibular stimulation during gait. Gait Posture 33:656-660. https://doi.org/10.1016/j.gaitpost.2011.02.017

18. MacDougall HG, Weber KP, McGarvie LA et al (2009) The video head impulse test: diagnostic accuracy in peripheral vestibulopathy. Neurology 73:1134-1141. https://doi.org/10.1212/ WNL.0b013e3181bacf85

19. Chen L, Halmagyi GM (2020) Video head impulse testing: from bench to bedside. Semin Neurol 40:5-17. https://doi. org/10.1055/s-0039-3402063

20. Yip CW, Glaser M, Frenzel C et al (2016) Comparison of the bedside head-impulse test with the video head-impulse test in a clinical practice setting: a prospective study of 500 outpatients. Front Neurol. https://doi.org/10.3389/fneur.2016.00058

21. Pogson JM, Taylor RL, McGarvie LA et al (2020) Head impulse compensatory saccades: visual dependence is most evident in bilateral vestibular loss. PLoS ONE 15:e0227406. https://doi. org/10.1371/journal.pone.0227406

22. Van Nechel C, Bostan A, Duquesne U et al (2019) Visual input is the main trigger and parametric determinant for catchup saccades during video head impulse test in bilateral vestibular loss. Front Neurol 10:1138. https://doi.org/10.3389/fneur.2018.01138

23. Mantokoudis G, Saber Tehrani AS, Kattah JC et al (2015) Quantifying the vestibulo-ocular reflex with video-oculography: nature and frequency of artifacts. Audiol Neurotol 20:39-50. https://doi. org/10.1159/000362780

24. Trinidad-Ruiz G, Rey-Martinez J, Matiño-Soler E et al (2020) Relevance of artifact removal and number of stimuli for video head impulse test examination. Ear Hear. https://doi.org/10.1097/ AUD.0000000000000849

25. Strupp M, Kichler A, McGarvie L, Kremmyda O (2018) The video head impulse test: a right-left imbalance. J Neurol 265:40-43
26. Heuberger M, Grill E, Sağlam M et al (2018) Usability of the video head impulse test: lessons from the population-based prospective KORA study. Front Neurol 9:659. https://doi. org/10.3389/fneur.2018.00659

27. Wenzel A, Hülse R, Thunsdorff C et al (2019) Reducing the number of impulses in video head impulse testing - it's the quality not the numbers. Int J Pediatr Otorhinolaryngol 125:206-211. https://doi.org/10.1016/j.ijporl.2019.07.013

28. Janky KL, Patterson JN, Shepard NT et al (2017) Effects of device on video head impulse test (vHIT) gain. J Am Acad Audiol 28:778-785

29. van Dooren TS, Starkov D, Lucieer FMP et al (2020) Comparison of three video head impulse test systems for the diagnosis of bilateral vestibulopathy. J Neurol. https://doi.org/10.1007/s0041 5-020-10060-w

30. Cleworth TW, Carpenter MG, Honegger F, Allum JHJ (2017) Differences in head impulse test results due to analysis techniques. J Vestib Res Equilib Orientat 27:163-172. https://doi. org/10.3233/VES-170614

31. Kim TS, Lim HW, Yang CJ et al (2018) Changes of video head impulse test results in lateral semicircular canal plane by different peak head velocities in patients with vestibular neuritis. Acta Otolaryngol 138:785-789. https://doi.org/10.1080/00016 489.2018.1481523

32. Judge PD, Rodriguez AI, Barin K, Janky KL (2018) Impact of target distance, target size, and visual acuity on the video head impulse test. Otolaryngol Head Neck Surg 159:739-742. https ://doi.org/10.1177/0194599818779908

33. Agrawal Y, Van De Berg R, Wuyts F et al (2019) Presbyvestibulopathy: diagnostic criteria Consensus document of the classification committee of the Bárány Society. J Vestib Res Equilib Orientat 29:161-170. https://doi.org/10.3233/VES-190672

34. Wettstein VG, Weber KP, Bockisch CJ, Hegemann SC (2016) Compensatory saccades in head impulse testing influence the dynamic visual acuity of patients with unilateral peripheral vestibulopathy. In: Journal of Vestibular Research: Equilibrium and Orientation. IOS Press, pp 395-402

35. Mantokoudis G, Saber Tehrani AS, Wong AL et al (2016) Adaptation and compensation of vestibular responses following superior canal dehiscence surgery. Otol Neurotol 37:1399-1405. https ://doi.org/10.1097/MAO.0000000000001196

36. Rey-Martinez J, Batuecas-Caletrio A, Matiño E, Perez Fernandez N (2015) HITCal: a software tool for analysis of video head impulse test responses. Acta Otolaryngol 135:886-894. https:// doi.org/10.3109/00016489.2015.1035401

37. Batuecas-Caletrio A, Santacruz-Ruiz S, Muñoz-Herrera A, Perez-Fernandez N (2014) The vestibulo-ocular reflex and subjective balance after vestibular schwannoma surgery. Laryngoscope 124:1431-1435. https://doi.org/10.1002/lary.24447

38. Batuecas-Caletrio A, Rey-Martinez J, Trinidad-Ruiz G et al (2017) Vestibulo-ocular reflex stabilization after vestibular schwannoma surgery: a story told by saccades. Front Neurol. https://doi.org/10.3389/fneur.2017.00015

39. Guajardo-Vergara C, Perez-Fernandez N (2020) A new and faster method to assess vestibular compensation: a cross-sectional study. Laryngoscope. https://doi.org/10.1002/lary.28505

40. Batuecas-Caletrio A, Trinidad-Ruiz G, Rey-Martinez J et al (2020) Oscillopsia in bilateral vestibular hypofunction. Ear Hear 41:323-329. https://doi.org/10.1097/AUD.0000000000000760

41. Jay DR, Cane D, Howe S (2019) Age is a greater influence on small saccades than target size in normal subjects on the horizontal video head impulse test. Front Neurol. https://doi. org/10.3389/fneur.2019.00328

42. de Waele C, Shen Q, Magnani C, Curthoys IS (2017) A novel saccadic strategy revealed by suppression head impulse testing of 
patients with bilateral vestibular loss. Front Neurol 8:419. https ://doi.org/10.3389/fneur.2017.00419

43. Shen Q, Magnani C, Sterkers O et al (2016) Saccadic velocity in the new suppression head impulse test: a new indicator of horizontal vestibular canal paresis and of vestibular compensation. Front Neurol 7:160. https://doi.org/10.3389/fneur.2016.00160

44. MacDougall HG, McGarvie LA, Halmagyi GM et al (2016) A new saccadic indicator of peripheral vestibular function based on the video head impulse test. Neurology 87:410-418. https://doi. org/10.1212/WNL.0000000000002827

45. Park JS, Lee JY, Nam W et al (2020) Comparing the suppression head impulse paradigm and the head impulse paradigm in vestibular neuritis. Otol Neurotol 41:E76-E82. https://doi.org/10.1097/ MAO.0000000000002453

46. Rey-Martinez J, Thomas-Arrizabalaga I, Espinosa-Sanchez JM et al (2018) Vestibulo-ocular reflex gain values in the suppression head impulse test of healthy subjects. Laryngoscope 128:23832389. https://doi.org/10.1002/lary.27107

47. Schubert MC, Herdman SJ, Tusa RJ (2002) Vertical dynamic visual acuity in normal subjects and patients with vestibular hypofunction. Otol Neurotol 23:372-377. https://doi. org/10.1097/00129492-200205000-00025

48. Tian J, Shubayev I, Demer J (2002) Dynamic visual acuity during passive and self-generated transient head rotation in normal and unilaterally vestibulopathic humans. Exp Brain Res 142:486495. https://doi.org/10.1007/s00221-001-0959-7

49. Vital D, Hegemann SCA, Straumann D et al (2010) A new dynamic visual acuity test to assess peripheral vestibular function. Arch Otolaryngol Neck Surg 136:686. https://doi. org/10.1001/archoto.2010.99

50. Li C, Beaumont JL, Rine RM et al (2014) Normative scores for the NIH toolbox dynamic visual acuity test from 3 to 85 years. Front Neurol 5:223. https://doi.org/10.3389/fneur.2014.00223

51. Verbecque E, Van Criekinge T, Vanloot D et al (2018) Dynamic Visual Acuity test while walking or running on treadmill: reliability and normative data. Gait Posture 65:137-142. https://doi. org/10.1016/j.gaitpost.2018.07.166

52. Guinand N, Pijnenburg M, Janssen M, Kingma H (2012) Visual acuity while walking and oscillopsia severity in healthy subjects and patients with unilateral and bilateral vestibular function loss. Arch Otolaryngol Neck Surg 138:301. https://doi.org/10.1001/ archoto.2012.4

53. Starkov D, Snelders M, Lucieer F, et al (2020) Bilateral vestibulopathy and age: experimental considerations for testing dynamic visual acuity on a treadmill. Manuscript submitted for publication

54. Ramat S, Colnaghi S, Boehler A et al (2012) A device for the functional evaluation of the VOR in clinical settings. Front Neurol 3:39. https://doi.org/10.3389/fneur.2012.00039

55. Colagiorgio P, Colnaghi S, Versino M, Ramat S (2013) A new tool for investigating the functional testing of the VOR. Front Neurol 4:165. https://doi.org/10.3389/fneur.2013.00165

56. Versino M, Colagiorgio P, Sacco S et al (2014) Reading while moving: the functional assessment of VOR. J Vestib Res 24:459464. https://doi.org/10.3233/VES-140531

57. Corallo G, Versino M, Mandalà M et al (2018) The functional head impulse test: preliminary data. J Neurol. https://doi. org/10.1007/s00415-018-8910-z

58. Starkov D, Guinand N, Lucieer F et al (2019) Restoring the highfrequency dynamic visual acuity with a vestibular implant prototype in humans. Audiol Neurotol. https://doi.org/10.1159/00050 3677

59. van Dooren TS, Lucieer FMP, Duijn S et al (2019) The functional head impulse test to assess oscillopsia in bilateral vestibulopathy. Front Neurol 10:365. https://doi.org/10.3389/fneur.2019.00365
60. Dietrich H, Wuehr M (2019) Selective suppression of the vestibulo-ocular reflex during human locomotion. J Neurol. https:// doi.org/10.1007/s00415-019-09352-7

61. Brandt T, Strupp M, Benson J (1999) You are better off running than walking with acute vestibulopathy. Lancet 354:746. https:// doi.org/10.1016/S0140-6736(99)03179-7

62. Halmagyi GM, Curthoys IS (1988) A clinical sign of canal paresis. Arch Neurol 45:737-739. https://doi.org/10.1001/archn eur.1988.00520310043015

63. Press S, Goetzinger CP, Karlsen EA, Stevens JH (1979) A study of five parameters of calorically-induced nystagmus in the clinical situation. undefined

64. Della Santina CC, Potyagaylo V, Migliaccio AA et al (2005) Orientation of human semicircular canals measured by three-dimensional multiplanar CT reconstruction. JARO J Assoc Res Otolaryngol 6:191-206. https://doi.org/10.1007/s10162-005-0003-x

65. BSA (2010) Recommended procedure: the caloric test. British Society of Audiology, Berkshire

66. Lightfoot GR (2004) The origin of order effects in the results of the bi-thermal caloric test. Int J Audiol 43:276-282. https://doi. org/10.1080/14992020400050037

67. Burnette E, Piker EG, Frank-Ito D (2018) Reevaluating order effects in the binaural bithermal caloric test. Am J Audiol 27:104-109. https://doi.org/10.1044/2017_AJA-17-0028

68. Skipper C, Knight R, Cane D (2019) Nystagmus duration after caloric irrigations. Int J Audiol. https://doi.org/10.1080/14992 027.2019.1703046

69. Jacobson GP, Newman CW, Kartush JM (1993) Handbook of balance function testing, xii. Mosby Year Book, St. Louis

70. Kim S, Oh Y-M, Koo J-W, Kim JS (2011) Bilateral vestibulopathy: clinical characteristics and diagnostic criteria. Otol Neurotol 32:812-817. https://doi.org/10.1097/MAO.0b013e31821a3b7d

71. Greisen O (1972) Pseudocaloric nystagmus. Acta Otolaryngol 73:341-343. https://doi.org/10.3109/00016487209138950

72. Möller C, Ödkvist LM (1989) The plasticity of compensatory Eye movements in bilateral vestibular loss: a study with low and high frequency rotatory tests. Acta Otolaryngol 108:345-354. https://doi.org/10.3109/00016488909125538

73. Leigh RJ, Zee DS (2006) The neurology of eye movements. Oxford University Press, Oxford

74. Van der Stappen A, Wuyts FL, Van de Heyning PH (2000) Computerized electronystagmography: normative data revisited. Acta Otolaryngol 120:724-730. https://doi.org/10.1080/0001648007 50000243

75. Möller C, Ödkvist L, White V, Cyr D (1990) The plasticity of compensatory eye movements in rotatory tests: 1 . The effect of alertness and eye closure. Acta Otolaryngol 109:15-24. https:// doi.org/10.3109/00016489009107410

76. Barnes GR (1993) Visual-vestibular interaction in the control of head and eye movement: the role of visual feedback and predictive mechanisms. Prog Neurobiol 41:435-472

77. Maes L, Dhooge I, De Vel E et al (2008) Normative data and test-retest reliability of the sinusoidal harmonic acceleration test, pseudorandom rotation test and velocity step test. J Vestib Res Equilib Orientat 18:197-208

78. Konijnenberg JJ, Kingma H (1995) Visuo-vestibular interaction measurements: an alternative for rotation tests with better discriminatory power? Acta Otolaryngol 115:194-198. https://doi. org/10.3109/00016489509125226

79. Demer JL, Honrubia V, Baloh RW (1994) Dynamic visual acuity: a test for oscillopsia and vestibulo-ocular reflex function. In: American Journal of Otology. pp 340-347

80. Fischer AJEM, Huygen PLM, Folgering HT et al (1995) Vestibular hyperreactivity and hyperventilation after whiplash 
injury. J Neurol Sci 132:35-43. https://doi.org/10.1016/0022510X(95)00118-L

81. Theunissen EJJM, Huygen PLM, Folgering HT (1986) Vestibular hyperreactivity and hyperventilation. Clin Otolaryngol 11:161169. https://doi.org/10.1111/j.1365-2273.1986.tb00123.x

82. Hain TC, Cherchi M, Perez-Fernandez N (2018) The Gain-Time constant product quantifies total vestibular output in bilateral vestibular loss. Front Neurol. https://doi.org/10.3389/fneur 2018.00396

83. Baloh RW, Jacobson KM, Beykirch K, Honrubia V (1989) Horizontal vestibulo-ocular reflex after acute peripheral lesions. Acta Otolaryngol 108:323-327. https://doi.org/10.3109/0001648890 9139069

84. Jenkins HA, Honrubia V, Baloh RH (1982) Evaluation of multiple-frequency rotatory testing in patients with peripheral labyrinthine weakness. Am J Otolaryngol Neck Med Surg 3:182-188. https://doi.org/10.1016/S0196-0709(82)80052-5

85. Bouveresse A, Kalfane K, Gentine A, et al (1998) Pseudorandom rotational stimuli of the vestibulo-ocular reflex in humans: normal values of the transfer function. undefined

86. Jenkins HA, Goldberg J Test-retest reliability of the rotatory test in normal subjects. pp 190-195

87. Li C-W, Hooper RE, Cousins VC (1991) Sinusoidal harmonic acceleration testing in normal humans. Laryngoscope 101:192196. https://doi.org/10.1288/00005537-199102000-00016

88. Wolfe JW, Engelken EJ, Kos CM (1978) Low-frequency harmonic acceleration as a test of labyrinthine function: basic methods and illustrative cases. Otolaryngology. https://doi. org/10.1177/019459987808600132

89. Hain T, Cherchi M, Yacovino D (2013) Bilateral Vestibular Loss. Semin Neurol 33:195-203. https://doi.org/10.1055/s-0033-13545 97

90. Curthoys IS (2010) A critical review of the neurophysiological evidence underlying clinical vestibular testing using sound, vibration and galvanic stimuli. Clin Neurophysiol 121:132-144

91. Noij KS, Herrmann BS, Rauch SD, Guinan JJ (2018) Toward optimizing vestibular evoked myogenic potentials: normalization reduces the need for strong neck muscle contraction. Audiol Neurotol 22:282-291. https://doi.org/10.1159/000485022

92. Noij KS, Van Tilburg MJ, Herrmann BS et al (2018) Toward optimizing VEMP: calculating VEMP inhibition depth with a generic template. Ear Hear 39:1199-1206. https://doi. org/10.1097/AUD.0000000000000579

93. van Tilburg MJ, Herrmann BS, Rauch SD et al (2019) Normalizing cVEMPs: which method is the most effective? Ear Hear 40:878-886. https://doi.org/10.1097/AUD.0000000000000668

94. Van Tilburg MJ, Herrmann BS, Guinan JJ, Rauch SD (2016) Increasing the stimulation rate reduces cVEMP testing time by more than half with no significant difference in threshold. Otol Neurotol 37:933-936. https://doi.org/10.1097/MAO.0000000000 001096

95. Van De Berg R, Rosengren S, Kingma H (2018) Laboratory examinations for the vestibular system. Curr Opin Neurol 31:111-116

96. Van Tilburg MJ, Herrmann BS, Guinan JJ, Rauch SD (2016) Serial cVEMP testing is sensitive to disease progression in ménière patients. Otol Neurotol 37:1614-1619. https://doi. org/10.1097/MAO.0000000000001213

97. Dyball AC, Govender S, Taylor RL et al (2020) Bone-conducted vestibular and stretch reflexes in human neck muscles. Exp Brain Res. https://doi.org/10.1007/s00221-020-05798-8

98. Colebatch JG, Halmagyi GM, Skuse NF (1994) Myogenic potentials generated by a click-evoked vestibulocollic reflex. J Neurol Neurosurg Psychiatry 57:190-197. https://doi.org/10.1136/ jnnp.57.2.190
99. Anupriya E, Kumar K (2019) Test-retest reliability of cervical and ocular vestibular evoked myogenic potential with simultaneous and sequential recording. Am J Audiol 28:414-421. https:// doi.org/10.1044/2019_AJA-IND50-18-0087

100. Takahashi K, Tanaka O, Kudo Y et al (2019) Effects of stimulus conditions on vestibular evoked myogenic potentials in healthy subjects. Acta Otolaryngol 139:500-504. https://doi. org/10.1080/00016489.2019.1592224

101. Papathanasiou ES (2019) Standardizing the way we perform and apply vestibular evoked myogenic potentials (VEMPs). Clin Neurophysiol Pract 4:37-38

102. Papathanasiou ES, Murofushi T, Akin FW, Colebatch JG (2014) International guidelines for the clinical application of cervical vestibular evoked myogenic potentials: an expert consensus report. Clin Neurophysiol 125:658-666

103. Piker EG, Jacobson GP, Burkard RF et al (2013) Effects of age on the tuning of the cVEMP and oVEMP. Ear Hear. https://doi. org/10.1097/AUD.0b013e31828fc9f2

104. Rosengren SM, Colebatch JG, Young AS et al (2019) Vestibular evoked myogenic potentials in practice: methods, pitfalls and clinical applications. Clin Neurophysiol Pract 4:47-68

105. Taylor RL, Welgampola MS, Nham B, Rosengren SM (2020) Vestibular-evoked myogenic potential testing in vestibular localization and diagnosis. Semin Neurol 40:018-032. https://doi. org/10.1055/s-0039-3402068

106. Papathanasiou ES, Straumann D (2019) Why and when to refer patients for vestibular evoked myogenic potentials: a critical review. Clin Neurophysiol 130:1539-1556

107. Fife TD, Satya-Murti S, Burkard RF, Carey JP (2018) Vestibular evoked myogenic potential testing Payment policy review for clinicians and payers. Neurol Clin Pract 8:129-134. https://doi. org/10.1212/CPJ.0000000000000430

108. Fife TD, Colebatch JG, Kerber KA et al (2017) Practice guideline: cervical and ocular vestibular evokedmyogenic potential testing: report of the guideline development, dissemination, and implementation subcommittee of the American Academy of Neurology. Neurology 89:2288-2296. https://doi.org/10.1212/ WNL.0000000000004690

109. Rizk HG, Liu YF, Strange CC et al (2020) Predictive value of vestibular evoked myogenic potentials in the diagnosis of Menière's disease and vestibular migraine. Otol Neurotol. https ://doi.org/10.1097/MAO.0000000000002636

110. Kharkheli E, Japaridze S, Kevanishvili Z et al (2019) Correlation between vestibular evoked myogenic potentials and disease progression in Ménière's disease. ORL 81:193-201. https://doi. org/10.1159/000496088

111. Özdemir D, Akpınar ÇK, Küçüköner Ö et al (2020) Vestibular evoked myogenic potential (VEMP) results in migraine and migrainous vertigo. Acta Otolaryngol 140:140-143. https://doi. org/10.1080/00016489.2019.1701202

112. Hu J, Chen Z, Zhang Y et al (2020) Vestibular dysfunction in patients with auditory neuropathy detected by vestibular evoked myogenic potentials. Clin Neurophysiol. https://doi. org/10.1016/j.clinph.2020.02.002

113. Li X, Gong S (2020) The effect of cochlear implantation on vestibular evoked myogenic potential in children. Laryngoscope. https://doi.org/10.1002/lary.28520

114. Merchant GR, Schulz KM, Patterson JN et al (2020) Effect of cochlear implantation on vestibular evoked myogenic potentials and wideband acoustic immittance. Ear Hear. https://doi. org/10.1097/AUD.0000000000000831

115. Jomin G, Kumar K, Ebenezer A (2019) Comparison of vestibular evoked myogenic potential and dizziness handicap inventory in patient with peripheral vestibular lesions between pre and post vestibular rehabilitation. Int Tinnitus J 23:69-73. https://doi. org/10.5935/0946-5448.20190012 
116. Oya R, Imai T, Takenaka Y et al (2019) Clinical significance of cervical and ocular vestibular evoked myogenic potentials in benign paroxysmal positional vertigo: a meta-analysis. Eur Arch Oto-Rhino-Laryngol 276:3257-3265

117. Ward BK, van de Berg R, van Rompaey V, et al (2020) Superior Semicircular Canal Dehiscence Syndrome (SCDS). Manuscript submitted for publication

118. Verrecchia L, Brantberg K, Tawfique Z, Maoli D (2019) Diagnostic accuracy of ocular vestibular evoked myogenic potentials for superior canal dehiscence syndrome in a large cohort of dizzy patients. Ear Hear 40:287-294. https://doi.org/10.1097/ AUD.0000000000000613

119. Noij KS, Herrmann BS, Guinan JJ, Rauch SD (2019) Toward optimizing cVEMP: 2,000-Hz tone bursts improve the detection of superior canal dehiscence. Audiol Neurotol 23:335-344. https ://doi.org/10.1159/000493721

120. Mach E (1875) Fundamentals of the theory of movement perception. Verlag von Wilhelm Engelmann, Leipzig

121. Dupuits B, Pleshkov M, Lucieer F et al (2019) A new and faster test to assess vestibular perception. Front Neurol 10:707. https ://doi.org/10.3389/fneur.2019.00707

122. Bermúdez Rey MC, Clark TK, Wang W et al (2016) Vestibular perceptual thresholds increase above the age of 40. Front Neurol 7:1-17. https://doi.org/10.3389/fneur.2016.00162

123. Kingma $H(2005)$ Thresholds for perception of direction of linear acceleration as a possible evaluation of the otolith function. BMC Ear Nose Throat Disord 88:82-87. https://doi.org/10.1186/14726815-5-Received

124. Grabherr L, Nicoucar K, Mast FW, Merfeld DM (2008) Vestibular thresholds for yaw rotation about an earth-vertical axis as a function of frequency. Exp Brain Res 186:677-681. https://doi. org/10.1007/s00221-008-1350-8

125. Klein SA (2001) Measuring, estimating, and understanding the psychometric function: a commentary. Percept. Psychophys. 63:1421-1455

126. Leek MR (2001) Adaptive procedures in psychophysical research. Percept Psychophys 63:1279-1292. https://doi. org/10.3758/BF03194543

127. Seemungal BM, Gunaratne IA, Fleming IO et al (2004) Perceptual and nystagmic thresholds of vestibular function in yaw. $\mathrm{J}$ Vestib Res 14:461-466

128. Hartmann M, Furrer S, Herzog MH et al (2013) Self-motion perception training: thresholds improve in the light but not in the dark. Exp Brain Res 226:231-240. https://doi.org/10.1007/s0022 1-013-3428-1

129. Gianna C, Heimbrand S, Gresty M (1996) Thresholds for detection of motion direction during passive lateral whole-body acceleration in normal subjects and patients with bilateral loss of labyrinthine function. In: Brain Research Bulletin. Elsevier Inc., pp 443-447

130. Gianna CC, Heimbrand S, Nakamura T, Gresty MA (1995) Thresholds for perception of lateral motion in normal subjects and patients with bilateral loss of vestibular function. Acta
Otolaryngol 115:343-346. https://doi.org/10.3109/0001648950 9125266

131. Bremova T, Caushaj A, Ertl M et al (2016) Comparison of linear motion perception thresholds in vestibular migraine and Menière's disease. Eur Arch Oto-Rhino-Laryngology 273:29312939. https://doi.org/10.1007/s00405-015-3835-y

132. Lewis RF, Priesol AJ, Nicoucar K et al (2011) Dynamic tilt thresholds are reduced in vestibular migraine. J Vestib Res Equilib Orientat 21:323-330. https://doi.org/10.3233/ VES-2011-0422

133. Merfeld DM, Priesol A, Lee D et al (2014) Potential solutions to several vestibular challenges facing clinicians. J Vestib Res 154:2262-2265. https://doi.org/10.1016/j.pain.2013.06.005.ReThinking

134. Agrawal Y, Bremova T, Kremmyda O et al (2013) Clinical testing of otolith function: perceptual thresholds and myogenic potentials. JARO J Assoc Res Otolaryngol 14:905-915. https://doi. org/10.1007/s10162-013-0416-X

135. van Stiphout, Lisa Florence L, Pleshkov M, van Rompaey V, et al (2020) Bilateral vestibulopathy decreases self-motion perception. Manuscript submitted for publication

136. Limviriyakul S, Luangsawang C, Suvansit K et al (2020) Video head impulse test and caloric test in definite Ménière's disease. Eur Arch Oto-Rhino-Laryngology 277:679-686. https://doi. org/10.1007/s00405-019-05735-8

137. Hannigan IP, Welgampola MS, Watson SRD (2019) Dissociation of caloric and head impulse tests: a marker of Meniere's disease. J Neurol

138. R M, RSM B, MM do CB-S, et al (2017) Sensitivity of caloric test and video head impulse as screening test for chronic vestibular complaints. Clinics 72

139. van Esch BF, Nobel-Hoff GEAJ, van Benthem PPG et al (2016) Determining vestibular hypofunction: start with the video-head impulse test. Eur Arch Oto-Rhino-Laryngology 273:3733-3739. https://doi.org/10.1007/s00405-016-4055-9

140. Fukushima M, Oya R, Nozaki K et al (2019) Vertical head impulse and caloric are complementary but react opposite to Meniere's disease hydrops. Laryngoscope 129:1660-1666. https ://doi.org/10.1002/lary.27580

141. Shugyo M, Ito T, Shiozaki T et al (2020) Comparison of the video head impulse test results with caloric test in patients with Meniere's disease and other vestibular disorders. Acta Otolaryngol. https://doi.org/10.1080/00016489.2020.1766700

142. Rey-Martinez J, Altuna X, Cheng K et al (2020) Computing endolymph hydrodynamics during head impulse test on normal and hydropic vestibular labyrinth models. Front Neurol 11:289. https://doi.org/10.3389/fneur.2020.00289

143. Leng Y, Liu B (2020) Dissociation of caloric and video head impulse tests in patients with delayed endolymphatic hydrops. Front Neurol 11:362. https://doi.org/10.3389/fneur.2020.00362

144. Lucieer F, Vonk P, Guinand N et al (2016) Bilateral vestibular hypofunction: insights in etiologies, clinical subtypes, and diagnostics. Front Neurol. https://doi.org/10.3389/fneur.2016.00026 